\title{
Probiotics and intestinal health effects: a clinical perspective
}

\author{
P. Marteau*, P. Seksik and R. Jian \\ Gastroenterology Department, Hôpital Européen Georges Pompidou, Assistance Publique des Hôpitaux de Paris, \\ 20 rue Leblanc, 75908 Paris CEDEX 15, France
}

\begin{abstract}
Probiotics are viable non-pathogenic micro-organisms which, when ingested, exert a positive influence on host health or physiology. We have critically analysed the evidence for the efficacy of specific probiotic strains in human gastrointestinal diseases. The best evidence can be obtained with randomised controlled trials which avoid bias. Good evidence has been obtained with several strains in the prevention or treatment of antibiotic-associated disorders, in the treatment (and to a lesser extent prevention) of gastroenteritis and acute diarrhoea and in the alleviation of lactose intolerance. We also analysed the recent randomised controlled trials performed in patients with Clostridium difficile or Helicobacter pylori, inflammatory bowel disease, irritable bowel syndrome, non-ulcer dyspepsia and colon cancer.
\end{abstract}

Probiotics: Intestine: Gastroenteritis: Inflammatory bowel disease: Antibiotic-associated diarrhoea

\section{Introduction}

Probiotics have been defined as viable non-pathogenic micro-organisms which, when ingested, exert a positive influence on host health or physiology (Schrezenmeir \& de Vrese, 2001). They consist either of bacteria, especially lactobacilli and bifidobacteria but also Escherichia coli, enterococci or yeast (Saccharomyces). Some products contain a single strain while others consist of mixtures of several strains. The evidence supporting their efficacy in the treatment or prevention of intestinal disorders is increasing owing to a more systematic approach (Marteau et al. 1993). This paper summarises the evidence for positive effects of some probiotics in intestinal health, focusing on recent data and discussing the perspectives. The levels of evidence are based on study design and the methodological quality of individual studies, the best evidence coming from randomised controlled trials (RCT) with minimal bias.

The strength of evidence for positive effects of probiotics in intestinal disorders is good for antibiotic-associated diarrhoea, gastroenteritis and lactose intolerance. It is rapidly increasing, although more slowly, for inflammatory bowel disease and intestinal infections.

\section{Antibiotic-associated intestinal disorders}

Intestinal disorders, especially diarrhoea, occur frequently in patients who receive antibiotics, and result from a decrease in the colonisation resistance and fermentation capacity of the endogenous intestinal flora. RCT have shown that several probiotics (but not all) can prevent or shorten antibiotic-associated intestinal disorders (mainly diarrhoea); (Bergogne-Berezin, 2000; Marteau et al. 2001). Good evidence for clinical efficacy has been obtained for Saccharomyces boulardii, Lactobacillus rhamnosus GG and Enterococcus faecium SF68 (Table 1). However, some trials using the same products were negative and the reason for the discrepancy between studies is unclear (Table 1). Dose-response studies are lacking but most positive trials have used large doses. The mechanism involved is also unclear as multiple biological effects of the probiotics may contribute to the clinical efficacy. For example, S. boulardii can favourably influence population levels of Clostridium difficile in the colon, toxin production, the signalling pathway induced by bacterial infection, and intestinal secretion (Elmer et al. 1996; Czeruka et al. 2000). The cost-effectiveness of the use of probiotics together with antibiotics has not been assessed. Experts often recommend probiotic prevention with an active strain in high-risk subjects such as elderly subjects or patients receiving several antibiotics or those who had previous episodes of antibiotic-associated intestinal disorders (Bergogne-Berezin, 2000).

\section{Gastroenteritis}

Gastroenteritis is the main cause of acute diarrhoea, a frequent disorder that heals, usually spontaneously, within a

\footnotetext{
Abbreviations: IBD, inflammatory bowel disease; IBS, irritable bowel syndrome; RCT, randomised controlled trial.

* Corresponding author: Dr P. Marteau, fax +33 15609 3554, email philippe.marteau@egp.ap-hop-paris.fr
} 
Table 1. Randomised controlled trials performed with Saccharomyces boulardii, Lactobacillus rhamnosus GG, and Enterococcus faecium SF68 to prevent antibiotic-associated diarrhoea

\begin{tabular}{|c|c|c|c|}
\hline Probiotic/antibiotic & Number of subjects & Diarrhoea probiotic $v$. placebo & Reference \\
\hline \multicolumn{4}{|l|}{ S. boulardii } \\
\hline$\beta$-Lactamins or tetracyclins & 388 & $4.5 \%$ v. $17.5 \% *$ & Adam et al. (1977) \\
\hline Miscellaneous & 180 & $9.5 \%$ v. $21.8 \% *$ & Surawicz et al. (1989) \\
\hline$\beta$-Lactamins & 193 & $7.2 \%$ v. $14.6 \% *$ & McFarland et al. (1995) \\
\hline Miscellaneous & 69 & $14 \%$ v. $20 \%$ (NS) & Lewis et al. (1998) \\
\hline \multicolumn{4}{|l|}{ L. rhamnosus GG } \\
\hline Miscellaneous & 188 & $7 \%$ v. $25 \% *$ & Vanderhoof et al. (1999) \\
\hline Miscellaneous & 119 & $5 \%$ v. $16 \% *$ & Arvola et al. (1999) \\
\hline Clarithromycin + tinidazole & 60 & $+^{*}$ & Armuzzi et al. (2001) \\
\hline Miscellaneous & 302 & $29.3 \%$ v. $29.9 \%$ (NS) & Thomas et al. (2001) \\
\hline \multicolumn{4}{|l|}{ E. faecium SF68 } \\
\hline Antituberculous & 200 & $5 \%$ v. $18 \% *$ & Borgia et al. (1982) \\
\hline Miscellaneous & 45 & $8.7 \%$ v. $27.2 \% *$ & Wunderlich et al. (1989) \\
\hline
\end{tabular}

few days. The use of oral rehydration solutions is the main treatment, especially in infants and elderly people, but it does not shorten the duration of diarrhoea.

\section{Curative treatment}

More than fifteen RCT demonstrated a beneficial effect of some but not all probiotic products in infantile or adult gastroenteritis (see references in Marteau et al. 2001). L. rhamnosus GG repeatedly shortened diarrhoea to about half in infants with rotavirus diarrhoea (Shornikova et al. 1997a). It also proved effective in the treatment of acute diarrhoea in children in Asia, Peru, Pakistan, Karelia (Raza et al. 1995; Pant et al. 1996; Shornikova et al. 1997a; Oberhelman et al. 1999). In a recent European RCT (Guandalini et al. 2000), 287 children aged 1-36 months with acute diarrhoea received an oral rehydration solution which was supplemented either with L. rhamnosus GG (at least $10^{9}$ cfu per $250 \mathrm{ml}$ ) or with a placebo. The duration of diarrhoea was significantly shortened by the probiotic in the children with rotavirus infection: $56 \pm 17 \mathrm{~h}$ versus $77 \pm 42 \mathrm{~h}$, but not in those who were rotavirus negative $(n=186)$. L. rhamnosus $\mathrm{GG}$ administration also shortened the duration of hospital stay (Guandalini et al. 2000). Heat-inactivated L. rhamnosus GG was clinically as effective as the viable lactobacillus in the prevention of diarrhoea in one study (Kaila et al. 1995). E. faecium strain SF68 significantly shortened diarrhoea in four RCT (Wunderlich et al. 1989). Other probiotics such as Lactobacillus casei strain Shirota (Sugita and Togawa, 1994) and Lactobacillus reuteri (Shornikova et al. 1997b) are probably also effective but there is less evidence as fewer studies have been performed.

\section{Prevention}

Saavedra et al. (1994) demonstrated for the first time that giving some probiotics to infants admitted to hospital could significantly reduce the risk of diarrhoea and shedding of rotavirus. In a double-blind placebo-controlled trial, fifty-five children admitted to a chronic medical care unit were randomised to receive a standard milk formula or the same plus Bifidobacterium bifidum and Streptococcus thermophilus. During follow-up, diarrhoea occurred in $7 \%$ of the children receiving the probiotics versus $31 \%$ of the controls, and the shedding of rotavirus was reduced (10\% versus $39 \%)$. Four trials have used the L. rhamnosus strain GG and provided conflicting results. In a double-blind RCT (Szajewska et al. 2001), eighty-one children aged 1-36 months who were hospitalised for reasons other than diarrhoea received either $L$. rhamnosus GG $6 \times 10^{9} \mathrm{cfu}$ or a placebo orally twice daily for the duration of their hospital stay. The probiotic reduced the risk of nosocomial diarrhoea $(6.7 \%$ versus $33.3 \%)$. In this study, the prevalence of rotavirus infection was similar in the L. rhamnosus GG and placebo groups (20\% versus $27.8 \%$ ) but the risk of rotavirus gastroenteritis was reduced $(27.2 \%$ versus $16.7 \%)$. Another doubleblind RCT performed in Italy included 269 children and failed to confirm the protective effect of $L$. rhamnosus GG against nosocomial infection with rotavirus (Mastretta et al. 2002). In another RCT which included 204 undernourished Peruvian children, L. rhamnosus GG had no preventive effect against diarrhoea in breast-fed infants but it reduced the risk of diarrhoea in non-breast-fed infants (4.7 episodes of diarrhoea per infant per year in the probiotic group versus 5.9 in the placebo group; Oberhelman et al. 1999). A Finnish study included 571 healthy children aged 1-6 years attending day care centres and who were followed for seven months during the winter. Half of the children received L. rhamnosus GG and the other half a placebo. The authors reported a trend for a decrease in respiratory infections but no effect on the risk of diarrhoea (Hatakka et al. 2001).

\section{Lactose intolerance}

Lactose maldigestion is a frequent situation in adults and in subjects with acute or chronic enteritis or bowel resection. Alleviation of lactose intolerance has been one of the first effects of probiotics to be demonstrated (Marteau et al. 1997). The best evidence has been obtained with yoghurt bacteria that contain high levels of lactase that is rapidly released when the bacteria are lysed by bile salts in the 
gastrointestinal tract (Marteau et al. 1990). Other probiotics containing lactase such as Lactobacillus acidophilus may also be active but their higher resistance to bile probably explains why they are less efficient than yoghurt bacteria (Marteau et al. 1997). In clinical practice, replacement of milk by yoghurt or fermented dairy products allows better digestion and/or decreases diarrhoea and other intolerance symptoms in subjects with lactose intolerance, in children with diarrhoea, and in subjects with short bowel syndrome (Arrigoni et al. 1994; Marteau et al. 1997).

Probiotic strains which are rapidly destroyed in the duodenum such as yoghurt bacteria, or lactococci could be used as vectors for enzymes or oral immunisation (Mercenier et al. 2000). We recently showed that an oral treatment with genetically modified Lactococcus lactis expressing Staphylococcus hyicus lipase enhanced lipid digestion in pigs with experimental pancreatic insufficiency (Drouault et al. 2001). The clinical interest of this new way of delivery needs to be studied in more detail.

\section{Intestinal infections and colonisation by pathogenic bacteria}

The protective effects of probiotics against intestinal infections have been demonstrated in animal models (Reid et al. 2001). Several mechanisms have been suggested which are not exclusive, such as production of various acids, hydrogen peroxide or bacteriocins, competition for nutrients or adhesion receptors, anti-toxin actions and stimulation of the immune system. Open studies have suggested a beneficial role of L. rhamnosus GG, S. boulardii and Lactobacillus plantarum LP299v during C. difficile-related infections. However, such observational studies do not provide strong evidence. Two placebo-controlled RCT demonstrated some efficacy of $S$. boulardii to decrease the risk of recurrence of C. difficile infection (McFarland et al. 1994; Surawicz et al. 2000). The first trial compared the efficacy of the standard antibiotic treatment combined either with $S$. boulardii $(1 \mathrm{~g} / \mathrm{d}$ for $28 \mathrm{~d})$ or with a placebo. The risk of recurrence was significantly reduced by the probiotic for the subjects who had had several episodes of $C$. difficile infection $(34.6 \%$ versus $64.7 \%)$ but not in the subjects treated for a first episode of $C$. difficile infection (McFarland et al. 1994). In the second study, a significant decrease in the risk of recurrence was observed in patients treated with a high dose of vancomycin plus $S$. boulardii versus those who received a high dose of vancomycin plus placebo (Surawicz et al. 2000).

Colonisation of the gastric mucosa by Helicobacter pylori is common and strongly associated with gastritis, duodenal and gastric ulcers, gastric carcinoma and lymph oma. Several probiotic strains, especially lactobacilli, exhibit antagonistic properties against $H$. pylori in vitro (Michetti, 2001). An open study showed a reduction of the urease activity of $H$. pylori in patients treated with a supernatant of Lactobacillus johnsonii LA1 (Michetti et al. 1999). In a recent trial by Felley et al. (2001), fifty-five volunteers with $H$. pylori infection received clarithromycin and were randomised to receive in addition either a fermented milk containing $L$. johnsonii LA1 or a placebo. The probiotic proved to significantly reduce the density of $H$. pylori and the intensity of gastric inflammation. Canducci et al. (2000) treated $120 \mathrm{H}$. pylori positive patients with the standard therapy (rabeprazole, clarithromycin and amoxicillin) together with either an inactivated culture of L. acidophilus or a placebo. The eradication rate of $H$. pylori was $87 \%$ in the probiotic group versus $70 \%$ in the control group $(P=0.02)$. Armuzzi et al. (2001) performed an RCT in sixty subjects with $H$. pylori infection who were treated with rabeprazole, clarithromycin and tinidazole. Half received L. rhamnosus GG for 14 days and the others received a placebo. The efficacy of the treatment did not differ between the two groups ( $83 \%$ versus $80 \%$ ) but tolerance to the treatment was better in the probiotic group.

\section{Traveller's diarrhoea}

Acute diarrhoea occurs frequently in travellers to high-risk areas. Three double-blind RCT have suggested some preventive efficacy of $L$. rhamnosus GG and S. boulardii (Oksanen et al. 1990; von Kollaritsch et al. 1993; Hilton et al. 1997). Unfortunately, these studies had some methodological problems and the evidence for the effect remains low. The first trial reported a reduction of diarrhoea by $L$. rhamnosus GG administration to subjects travelling to one destination in Turkey (Oksanen et al. 1990); however, the effect was not observed in subjects travelling to another destination. Overall, the reduction of the risk was not significant. In the second RCT, 400 American travellers received L. rhamnosus GG or a placebo (Hilton et al. 1997). More than one third were excluded from the analysis because they did not take the medication. When considering only the subjects who took the capsules, the risk of diarrhoea was $3.9 \%$ with the probiotic versus $7.4 \%$ with the placebo $(P=0.05)$. Although these results are interesting and strengthen the interest in the field, the statistical analysis based only on subgroups in the two studies (and not on an intention to treat basis) is questionable. The same limitation applies for the RCT with S. boulardii (von Kollaritsch et al. 1993), as only 1016 out of the 3000 Austrian travellers were compliant. Although it is not possible to medically recommend any probiotic at the present time to prevent traveller's diarrhoea, the likelihood for some agents to be effective is high and more thorough studies need to be performed.

\section{Inflammatory bowel disease}

Inflammatory bowel disease (IBD) is characterised by chronic intestinal inflammation of unknown origin and seems to be influenced by some members of the endogenous flora (Sartor, 1997). Several RCT have recently been performed with probiotics in various IBD-related conditions. The evidence for a relevant effect is now sufficiently strong to prescribe three probiotics to patients: VSL\#3, E. coli Nissle 1917 and S. boulardii. VSL\#3 (CSL, Milan, Italy) contains a mixture of four strains of lactobacilli (L. casei, L. plantarum, L. acidophilus, $L$. bulgaricus), three strains of bifidobacteria (B. longum, $B$. breve, B. infantis) and one strain of $S$. thermophilus. 
E. coli Nissle 1917 is a well defined non-pathogenic $E$. coli, and $S$. boulardii is a non-pathogenic yeast.

\section{Ulcerative colitis}

Three double-blind RCT compared the efficacy of E. coli Nissle 1917 to mesalazine, i.e. the standard treatment, for the maintenance of remission in ulcerative colitis (Kruis et al. 1997; Rembacken et al. 1999; Kruis et al. 2001). The effects did not differ between the probiotic and the anti-inflammatory treatment and the authors concluded that the probiotic was effective. However, it must be stressed that the demonstration of the superiority of the probiotic over placebo has not been made and that the anti-inflammatory treatment used as control in these studies was not optimally effective. In the first trial (Kruis et al. 1997), 120 patients with inactive ulcerative colitis received either $1.5 \mathrm{~g} / \mathrm{d}$ of mesalazine or $5 \times 10^{10}$ viable $E$. coli Nissle 1917. After 12 weeks, both treatments seemed equally effective, as $11.3 \%$ of the subjects receiving mesalazine and $16 \%$ of those receiving the probiotic had relapsed (no significant difference). However, the study was judiciously criticised, as its statistical power was low (because of the short duration of the treatment). In the second trial, E. coli strain Nissle 1917 was compared to mesalazine in 116 patients with ulcerative colitis followed for one year (Rembacken et al. 1999). All patients were also initially given a 1-week course of oral gentamycin and steroids. Remission was obtained in $75 \%$ of the patients in the mesalazine group versus $68 \%$ in the $E$. coli group (no significant difference). When remission was reached, the steroids were stopped, and the dose of mesalazine was reduced to $1.2 \mathrm{~g} / \mathrm{d}$. After 1 year, relapse occurred in $73 \%$ of the patients in the mesalazine group versus $67 \%$ in the $E$. coli group (no significant difference). This second trial was criticised, as the relapse rate in the mesalazine group was far higher than expected from the literature (i.e. $30 \%$ ). In a third trial (Kruis et al. 2001), 327 patients with quiescent ulcerative colitis received either the probiotic or mesalazine $1.5 \mathrm{~g} / \mathrm{d}$ for 1 year. The relapse rate was $45 \%$ in the probiotic group versus $36.4 \%$ in the mesalazine group (no significant difference).

\section{Pouchitis}

Gionchetti et al. (2000a) performed a double-blind RCT comparing the effect of VSL\#3 and placebo to prevent recurrence of chronic relapsing pouchitis. Forty patients with chronic relapsing pouchitis were studied. Remission was induced by one month of ciprofloxacin and rifabutin, and the probiotic mixture $(6 \mathrm{~g} / \mathrm{d})$ or the placebo were then prescribed for nine months. A relapse occurred in $15 \%$ of the subjects in the VSL\#3 group versus $100 \%$ in the placebo group $(P<0 \cdot 001)$. The same authors studied the effect of VSL\#3 to prevent pouchitis in forty patients who had ileo-pouch anal anastomosis for ulcerative colitis (Gionchetti et al. 2000b). Patients received either VSL\#3 $(3 \mathrm{~g} / \mathrm{d})$ or placebo for one year after surgery. The risk of pouchitis was significantly lower in the probiotic group: $10 \%$ versus $40 \%$.

\section{Crohn's disease}

In a double-blind RCT, thirty-two patients with Crohn's disease received either $1 \mathrm{~g} / \mathrm{d}$ of $S$. boulardii plus mesalazine $2 \mathrm{~g} / \mathrm{d}$ or mesalazine $3 \mathrm{~g} / \mathrm{d}$ for 1 year to prevent relapse (Guslandi et al. 2000). Fewer patients relapsed in the probiotic group (1/16 versus 6/16). Campieri et al. (2000) compared the efficacy of a combination of rifaximin $1.8 \mathrm{~g} / \mathrm{d}$ for three months followed by either VSL\#3 or mesalazine $4 \mathrm{~g} / \mathrm{d}$ to prevent postoperative recurrence of Crohn's disease in forty patients. After one year, the risk of severe endoscopic relapse was $20 \%$ in the probiotic group versus $40 \%$ in the control group. Malchow (1997) in a double-blind RCT treated twenty-eight subjects suffering from Crohn's disease of the colon with E. coli Nissle 1917 or placebo. The rate of relapse was significantly lower in the probiotic group (33\% versus $63 \%)$. These promising trials need to be confirmed with a higher number of patients and more rigorous design.

\section{Irritable bowel syndrome and non-ulcer dyspepsia}

Some probiotics, especially acidophilus or bifidus milks, have been reported to relieve constipation in short uncontrolled series (Marteau et al. 1993). However, these studies were not controlled. Two RCT showed that a milk fermented by Bifidobacterium animalis strain DN-173 010 shortened colonic transit time in healthy women (Bouvier et al. 2001; Marteau et al. 2002). This was also observed in elderly subjects (Méance et al. 2002). Halpern et al. (1996) showed in a randomised, double-blind, cross-over trial that administration of heat-killed lactobacilli (Lacteol fort $^{\circledR}$ ) for six weeks was more efficient than placebo to relieve symptoms of irritable bowel syndrome (IBS). However, the low number of patients included and the poor compliance to treatment do not allow any definitive conclusion. Hentschel et al. (1997) assessed the efficacy of two probiotic preparations containing lactobacilli and $E$. coli (Hylac ${ }^{\circledR}$ and Hylac $\mathrm{N}$ forte ${ }^{\circledR}$, Germany) in 126 subjects suffering from non-ulcer dyspepsia, and did not observe any amelioration. In a recent RCT, there was no difference between L. rhamnosus GG $10^{10} \mathrm{cfu} / \mathrm{d}$ and the placebo to alleviate symptoms of IBS in twenty-four patients (O'Sullivan \& O'Morain, 2000). At the present time, the level of evidence that probiotics may help subjects with IBS or non-ulcer dyspepsia is low and no recommendation can be made.

\section{Colon cancer}

The endogenous flora and the immune system play a role in the modulation of carcinogenesis, and some probiotics seem effective to prevent or help treat tumours in animal models. Several trials have shown that some probiotics may reproducibly decrease the faecal levels of enzymes, mutagens, and secondary bile salts that may be involved in colon carcinogenesis (Wollowski et al. 2001). In addition, some epidemiological studies suggested that consumption of fermented dairy products might have protective effects against large colon adenomas (Boutron et al. 
1996). The prospect of using probiotics to decrease colon cancer risk is thus open and intervention trials are needed.

\section{Conclusions}

Probiotics allow modulation of the endogenous intestinal flora and the immune system and can be used to modulate activities of the gastrointestinal tract. The evidence for positive effects of some probiotics in specific clinical situations is now strong, owing to a more systematic approach. Further research is needed particularly RCT. All the clinical trials described in this paper contribute to our view of the potential application of probiotics in the future. Important developments in this field can be expected, and the use of genetically modified probiotics could provide even further opportunities.

\section{References}

Adam J, Banet A \& Banet-Bellet C (1977) Essais cliniques contrôlés en double insu de l'Ultralevure lyophylisée (Double-blind controlled trials with Saccharomyces boulardii - Ultralevure). Gazette Médicale de France 84, 2072-2078.

Armuzzi A, Cremonini F, Bartolozzi F, Canducci F, Candelli M, Ojetti V, Cammarota G, Anti M, De Lorenzo A, Pola P, Gasbarrini G, Gasbarrini A (2001) The effect of oral administration of Lactobacillus GG on antibiotic-associated gastrointestinal side-effects during Helicobacter pylori eradication therapy. Alimentary Pharmacology \& Therapeutics 15, $163-169$.

Arrigoni E, Marteau P, Briet F, Pochart P, Rambaud JC \& Messing B (1994) Tolerance and absorption of lactose from milk and yoghurt during short bowel syndrome in man. American Journal of Clinical Nutrition 60, 926-929.

Arvola T, Laiho K, Torkkeli S, Mykkanen H, Salminen S, Maunula L \& Isolauri E (1999) Prophylactic Lactobacillus GG reduces antibiotic-associated diarrhea in children with respiratory infections: a randomized study. Pediatrics 104, 5, e64.

Bergogne-Berezin E (2000) Treatment and prevention of antibiotic associated diarrhea. International Journal of Antimicrobial Agents 16, 521-526.

Borgia M, Sepe N, Brancato V, Costa G, Simone P, Borgia R \& Lugli R (1982) A controlled clinical study on Streptococcus faecium preparation for the prevention of side reactions during long-term antibiotic treatments. Current Therapeutic Research 31, 265-271.

Boutron MC, Faivre J, Marteau P, Couillault C, Senesse P \& Quipourt V (1996) Calcium, phosphorus, vitamin D, dairy products and colorectal carcinogenesis: a French case-control study. British Journal of Cancer 74, 145-151.

Bouvier M, Méance S, Bouley C, Berta JL \& Grimaud JC (2001) Effects of consumption of a milk fermented with the probiotic strain Bifidobacterium animalis DN-173 010 on colonic transit times in healthy humans. Bioscience and Microflora 20, 43-48.

Campieri M, Rizzello F, Venturi A, Poggioli G, Ugolini F, Helwig U, Amadini C, Romboli E \& Gionchetti P (2000) Combination of antibiotic and probiotic treatment is efficacious in prophylaxis of post-operative recurrence of Crohn's disease: a randomized controlled study vs mesalamine. Gastroenterology 118, G4179.

Canducci F, Armuzzi A, Cremonini F, Cammarota G, Bartolozzi F, Pola P, Gasbarrini G \& Gasbarrini A (2000) A lyophilized and inactivated culture of Lactobacillus acidophilus increases
Helicobacter pylori eradication rates. Alimentary Pharmacology \& Therapeutics 14, 1625-1629.

Czeruka D, Dahan S, Mograbi B, Rossi B \& Rampal P (2000) Saccharomyces boulardii preserves the barrier function and modulates the signal transduction pathway induced in enteropathogenic Escherichia coli-infected T84 cells. Infection and Immunity 68, 5998-6004.

Drouault S, Juste C, Marteau P, Renault P \& Corthier G (2001) Oral treatment with genetically modified Lactococcus lactis expressing Staphylococcus hyicus lipase enhances lipid digestion in pigs with experimental pancreatic insufficiency. Gastroenterology 120, A3642 (abstract).

Elmer GW, Surawicz CM \& McFarland LV (1996) Biotherapeutic agents. A neglected modality for the treatment and prevention of selected intestinal and vaginal infections. Journal of the American Medical Association 275, 870-876.

Felley CP, Corthesy-Theulaz I, Rivero JL, Sipponen P, Kaufmann M, Bauerfeind P, Wiesel PH, Brassart D, Pfeifer A, Blum AL \& Michetti P (2001) Favourable effect of an acidified milk (LC-1) on Helicobacter pylori gastritis in man. European Journal of Gastroenterology and Hepatology 13, 25-29.

Gionchetti P, Rizzello F, Venturi A, Brigidi P, Matteuzzi D, Bazzocchi G, Poggioli G, Miglioli M \& Campieri M (2000a) Oral bacteriotherapy as maintenance treatment in patients with chronic pouchitis: a double-blind, placebo-controlled trial. Gastroenterology 119, 305-309.

Gionchetti P, Rizzello F, Venturi A, Helwig U, Amadini C, Lammers KM, Ugolini F, Poggioli G \& Campieri M (2000b) Prophylaxis of pouchitis onset with probiotic therapy: a double-blind, placebo controlled trial. Gastroenterology 118, G1214.

Guandalini S, Pensabene L, Zikri MA, Dias JA, Casali LG, Hoekstra H, Kolacek S, Massar K, Micetic-Turk D, Papadopoulou A, de Sousa JS, Sandhu B, Szajewska H \& Weizman Z (2000) Lactobacillus GG administered in oral rehydration solution to children with acute diarrhea: a multicenter European trial. Journal of Pediatric Gastroenterology and Nutrition 30, 54-60.

Guslandi M, Mezzi G, Sorghi M \& Testoni PA (2000) Saccharomyces boulardii in maintenance treatment of Crohn's disease. Digestive Disease and Science 45, 1462-1464.

Halpern GM, Prindiville T, Blanckenburg M, Hsia $\mathrm{T}$ \& Gerschwin ME (1996) Treatment of irritable bowel syndrome with Lacteol fort: a randomized, double-blind, cross-over trial. American Journal of Gastroenterology 91, 1579-1585.

Hatakka K, Savilahti E, Ponka A, Meurman JH, Poussa T, Nase L, Saxelin M \& Korpela R (2001) Effect of long term consumption of probiotic milk on infections in children attending day care centres: double-blind, randomised trial. British Medical Journal 322, 1327.

Hentschel C, Bauer J, Dill N, Blaut B, Jahnel M, Lindner M, Brinkhaus B, Shönekäs H, Kohnen R, Ernst E \& Hahn E (1997) Complementary medicine in non-ulcer dyspepsia: is alternative medicine a real alternative? A randomized placebo-controlled double-blind clinical trial with two probiotic agents - Hylac $^{\circledR}$ and Hylac ${ }^{\circledR}$ forte. Gastroenterology 112, A146.

Hilton E, Kolakowski P, Singer C \& Smith M (1997) Efficacy of Lactobacillus GG as a diarrheal preventive in travellers. Journal of Travel Medicine 4, 41-43.

Kaila M, Isolauri E, Saxelin M, Arvilommi H \& Vesikari T (1995) Viable versus inactivated lactobacillus strain GG in acute rotavirus diarrhoea. Archives of Diseases of Childhood 72, 51-53.

Kruis W, Fric P \& Stolte M (2001) Maintenance of remission in ulcerative colitis is equally effective with Escherichia coli 
Nissle 1997 and with standard mesalamine. Gastroenterology 120, A139.

Kruis W, Schütz E, Fric P, Fixa B, Judmaier G \& Stolte M (1997) Double-blind comparison of an oral Escherichia coli preparation and mesalazine in maintaining remission of ulcerative colitis. Alimentary Pharmacology \& Therapeutics 1, 853-858.

Lewis SJ, Potts LF \& Barry RE (1998) The lack of therapeutic effect of Saccharomyces boulardii in the prevention of antibiotic-related diarrhoea in elderly patients. Journal of Infection 36, $171-174$.

McFarland LV, Surawicz CM, Greenberg RN, Elmer GW, Moyer KA, Melcher SA, Brown KE \& Cox JL (1995) Prevention of beta-lactam-associated diarrhea by Saccharomyces boulardii compared with placebo. American Journal of Gastroenterology 90, 439-448.

McFarland LV, Surawicz CM, Greenberg RN, Fekety R, Elmer GW, Moyer KA, Melcher SA, Bowen KE, Cox JL, Noorani Z, Harrington G, Rubin M \& Greenwald D (1994) A randomized placebo-controlled trial of Saccharomyces boulardii in combination with standard antibiotics for Clostridium difficile disease. Journal of the American Medical Association 271, 1913-1918.

Malchow HA (1997) Crohn's disease and Escherichia coli. A new approach in therapy to maintain remission of colonic Crohn's disease? Journal of Clinical Gastroenterology 25, 653-658.

Marteau P, Cuillerier E, Mèance S, Gerhardt MF, Myara A, Bouvier M, Bouley C, Tondu F, Bommelaer G \& Grimaud JC (2002) Bifidobacterium animalis strain DN-173 010 shortens the colonic transit time in healthy women: a double-blind randomised controlled study. Alimentary Pharmacology and Therapeutics 16, 587-593.

Marteau P, Flourié B, Pochart P, Chastang C, Desjeux JF \& Rambaud JC (1990) Role of the microbial lactase (EC 3.2.123) activity from yogurt on the intestinal absorption of lactose: an in vivo study in lactase deficient humans. British Journal of Nutrition 64, 71-79.

Marteau P, Pochart P, Bouhnik Y \& Rambaud JC (1993) Fate and effects of some transiting microorganisms in the human gastrointestinal tract. World Review of Nutrition and Dietetics 74, $1-21$.

Marteau P, Vesa T \& Rambaud JC (1997) Lactose maldigestion. In Probiotics, pp. 65-88 [R Fuller, editor]. London: Chapman \& Hall.

Marteau PR, Vrese MD, Cellier CJ \& Schrezenmeir J (2001) Protection from gastrointestinal diseases with the use of probiotics. American Journal of Clinical Nutrition 73, Suppl. 2, 430S$436 \mathrm{~S}$.

Mastretta E, Longa P, Laccisaglia A, Balbo L, Russo R, Mazzaccara A \& Gianino P (2002) Rotavirus nosocomal infections in infants: is Lactobacillus GG effective in prevention? Journal of Pediatric Gastroenterology and Nutrition. In press.

Méance S, Cayuela C, Turchet P, Raimondi A, Lucas C \& Antoine JM (2001) A fermented milk with a Bifidobacterium probiotic strain DN-173 010 shortened oro-fecal gut transit time in elderly. Microbiology and Ecology in Health and Disease. In press.

Mercenier A, Muller-Alouf H \& Grangette C (2000) Lactic acid bacteria as live vaccines. Current Issues of Molecular Biology 2, 17-25.

Michetti P (2001) Lactobacilli for the management of Helicobacter pylori. Nutrition 17, 268-269.

Michetti P, Dorta G, Wiesel PH, Brassart D, Verdu E, Herranz M, Felley C, Porta N, Rouvet M, Blum AL \& Corthesy-Theulaz I (1999) Effect of whey-based culture supernatant of Lactobacillus acidophilus (johnsonii) La1 on Helicobacter pylori infection in humans. Digestion 60, 203-209.

Oberhelman RA, Gilman RH, Sheen P, Taylor DN, Black RE,
Cabrera L, Lescano AG, Meza R \& Madico GA (1999) Placebo-controlled trial of Lactobacillus GG to prevent diarrhea in undernourished Peruvian children. Journal of Pediatrics 134, $15-20$.

Oksanen PJ, Salminen S, Saxelin M, Hamalainen P, IhantolaVormisto A, Muurasniemi-Isoviita L, Nikkari S, Oksanen T, Porsti I, Salminen E, Siitonen S, Stuckey H, Toppila A \& Vapaatalo H (1990) Prevention of traveller's diarrhea by Lactobacillus GG. Annals of Medicine 22, 53-56.

O'Sullivan MA \& O'Morain CA (2000) Bacterial supplementation in the irritable bowel syndrome. A randomised doubleblind placebo-controlled crossover study. Digestive and Liver Disease 32, 294-301.

Pant AR, Graham SM, Allen SJ, Harikul S, Sabchareon A, Cuevas L \& Hart CA (1996) Lactobacillus GG and acute diarrhoea in young children in the tropics. Journal of Tropical Pediatrics 42, 162-165.

Raza S, Graham SM, Allen SJ, Sultana S, Cuevas L \& Hart CA (1995) Lactobacillus GG promotes recovery from acute nonbloody diarrhea in Pakistan. Pediatric Infectious Disease Journal 14, 107-111.

Reid G, Howard J \& Gan BS (2001) Can bacterial interference prevent infection? Trends in Microbiology 9, 424-428.

Rembacken BJ, Snelling AM, Hawkey PM, Chalmers DM \& Axon AT (1999) Non-pathogenic Escherichia coli versus mesalazine for the treatment of ulcerative colitis: a randomised trial. Lancet 354, 635-639.

Saavedra JM, Bauman NA, Oung I, Perman JA \& Yolken RH (1994) Feeding of Bifidobacterium bifidum and Streptococcus thermophilus to infants in hospital for prevention of diahrroea and shedding of rotavirus. Lancet 344, 1046-1049.

Sartor RB (1997) Role of the enteric microflora in the pathogenesis of intestinal inflammation and arthritis. Alimentary Pharmacology \& Therapeutics 11, Suppl. 3, 17-22.

Schrezenmeir J \& de Vrese M (2001) Probiotics, prebiotics and synbiotics - approaching a definition. American Journal of Clinical Nutrition 73, Suppl. 2, 361s-364s.

Shornikova AV, Casas IA, Mykkanen H, Salo E \& Vesikari T (1997a) Bacteriotherapy with Lactobacillus reuteri in rotavirus gastroenteritis. Pediatric Infectious Disease Journal 16, 11031107.

Shornikova AV, Isolauri E, Burkanova L, Lukovnikova S \& Vesikari T (1997b) A trial in the Karelian Republic of oral rehydration and Lactobacillus GG for treatment of acute diarrhoea. Acta Paediatrica 86, 460-465.

Sugita T \& Togawa M (1994) Efficacy of lactobacillus preparation biolactis powder in children with rotavirus enteritis. Japanese Journal of Pediatrics 47, 2755-2762.

Surawicz CM, Elmer GW, Speelman P, McFarland LV, Chinn J \& van Belle G (1989) Prevention of antibiotic associated diarrhea by Saccharomyces boulardii: a prospective study. Gastroenterology 96, 981-988.

Surawicz CM, McFarland LV, Greenberg RN, Rubin M, Fekety $\mathrm{R}$, Mulligan ME, Garcia RJ, Brandmarker S, Bowen K, Borjal D \& Elmer GW (2000) The search for a better treatment for recurrent Clostridium difficile disease: use of high-dose vancomycin combined with Saccharomyces boulardii. Clinical Infectious Disease 31, 1012-1017.

Szajewska H, Kotowska M, Mrukowicz JZ, Armanska M \& Mikolajczyk W (2001) Efficacy of Lactobacillus GG in prevention of nosocomial diarrhea in infants. Journal of Pediatrics 138, 361-365.

Thomas MR, Litin SC, Osmon DR, Corr AP, Weaver AL \& Lohse CM (2001) Lack of effect of Lactobacillus GG on antibiotic-associated diarrhea: a randomized, placebo-controlled trial. Mayo Clinic Proceedings 76, 883-889.

Vanderhoof JA, Whitney DB, Antonson DL, Hanner TL, Lupo JV 
\& Young RJ (1999) Lactobacillus GG in the prevention of antibiotic-associated diarrhea in children. Journal of Pediatrics 135, 564-568.

von Kollaritsch H, Holst H, Grobara P \& Wiedermann G (1993) Prophylaxe der Reisediarrhoe mit Saccharomyces boulardii. Ergebnisse einer Plazebokontrollierten Doppelblindstudie (Prevention of traveler's diarrhea with Saccharomyces boulardii. Results of a placebo controlled double-blind study). Forstchritt Medizin 111, $153-156$.
Wollowski I, Rechkemmer G \& Pool-Zobel BL (2001) Protective role of probiotics and prebiotics in colon cancer. American Journal of Clinical Nutrition 73, Suppl. 2, 451S-455S.

Wunderlich PF, Braun L, Fumagalli I, D’Apuzzo V, Heim F, Karly M, Lodi R, Politta G, Vonbank F \& Zeltner L (1989) Double-blind report on the efficacy of lactic acid-producing Enterococcus SF68 in the prevention of antibiotic-associated diarrhoea and in the treatment of acute diarrhoea. Journal of Internal Medicine Research 17, 333-338. 